\title{
The Development of Semantic Web to Search Student Final Study Collections (Work Practice and Final Project)
}

\author{
Lasmedi Afuan \\ Departement of Computer Science, UGM \\ Central Java \\ Indonesia
}

\author{
Ahmad Ashari \\ Departement of Computer Science, UGM \\ Central Java \\ Indonesia
}

\begin{abstract}
This research aims to implement semantic web on student final study domain (work practice and final project ). Implementation of semantic web utilizing RAP library as RDF API, SPARQL as a query to RDF access, and PHP as the server-side scripting language. The result of this research is semantic web which can store knowledge of final study report collections.
\end{abstract}

\section{General Terms}

Semantic web, ontology, semantic search.

\section{Keywords}

Semantic web, ontology, final study, rdf api, sparql.

\section{INTRODUCTION}

Information technology has developed very rapidly, one of which is the development of internet technology. On the internet, a very popular service at this time is a web (WWW). Web a source of data is very large and very valuable to each user because in the interconnected web document and can be accessed via an Internet connection[1]. The semantic web is a part of the web technologies that exist today, with the semantic web, the website is not only understandable by humans, but also can be understood by machines (machine readable). The semantic web is able to understand the meaning of a word or a concept and be able to understand the logical relationship among them. Semantic web so that only the information needed by the user.

Final study (Work Practice and Final Project) is one of the subjects that must be taken by students in both high school and university. At the final study (KP / TA) students are required to write the work or research in the form of reports. On the Information Engineering study program Unsoed collection of practical work and a final project that has been completed, submitted to the supervisor and library. Problems arise when professors or students want to search titles, abstracts or reports KP / TA, often have difficulty. Although already available library information system (SIMPUS). However, the system still uses SIMPUS search on keywords, so the results displayed are still quite dependent on the keywords entered by the user. To overcome these problems, this study proposed to implement a semantic Web to search student final study collections (Work Practice and Final Project)".

\section{LITERATURE REVIEW}

A Based on research [2][3], research [2] discusses the semantic web application to determine the choice of lane Trans Jogja bus, the steps being taken are divided into 2 ontology design and system design, the design of ontologies produce class among other properties are class TempatTujuan BerangkatdariShelter property, JalurYangDigunakan and
ShelterTerdekat type object type. While the properties of the address, description, nama_tujuan and rekomendasi_jalur type datatype. Implementation ontology using protégé. Information search Trans Jogja bus lanes by utilizing the Trans Jogja bus lanes ontology as a knowledge base can help the user to find relevant pathways

Other research related to the semantic web is also performed by [4] build ontology model for flight information using protégé. By using protégé, knowledge models flight schedule drawn up in the form of a hierarchical ontology classes, slots and instant. The model is able to describe the ontology arranged flight schedule information in a more semantically. And besides that, from the model that has been developed shows that the number of ways users (according to the perceptions of each) to search flight information or query results can be formed more easily.

Research conducted [5] applying semantic web on the domain ontology law to provide for the general user services easy and convenient to access information such as legal professionals.

From the results of studies and research above shows that the semantic web has been implemented widely in a variety of systems, and can be a solution for knowledge-based search.

\section{FUNDAMENTAL}

\subsection{Semantic Web}

The semantic web is a new generation of the web that already exist today, the semantic web is an evolution of the WWW (World Wide Web) proposed by Tim Berners-Lee in 1999. With the semantic web, a web not only understood by the human (users) will but it can also be understood by the machine / computer (machine readable). The goal of the architecture of semantic web is to provide the knowledge representation of LOD (Linked of data) that allows the machine / computer processes on a global scale [3]. Semantic Web is defined as a set of technologies, which allow computers to understand the meaning of an information based on metadata, ie information about the content of the information. With the metadata, the computer should be able to interpret the results of income information so search results become more detailed and precise. W3C defines the metadata format is the Resource Description Framework (RDF). Each unit of RDF consists of three compositions, namely subject, predicate, and object. Subject and predicate is an entity that is indicated by the text, while the predicate is a composition that explains the viewpoint of the subject described object. The most interesting part of RDF that object can be a subject that will be explained by other objects, so the object or entries can be explained clearly and in detail and in accordance with the wishes of users who provide input [1]. In general, the semantic web architecture can be seen in figure 1 . 


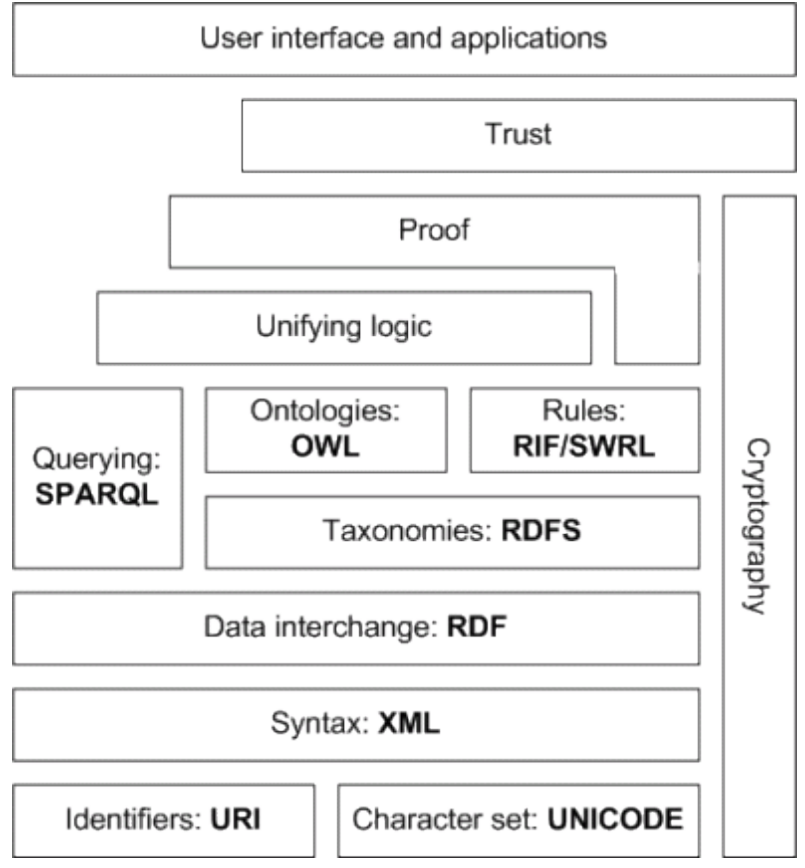

Figure 1. Architecture of Semantic Web

W3C call out semantic web architecture as the semantic web layer cake. $\mathrm{W} 3 \mathrm{C}$ recommends the semantic web activity, there are several layers of architecture of semantic web, among others [1]

1. URI/IRI, ensuring the use of a set of characters that have been agreed internationally and provides tools to identify objects in the semantic web.

2. Layer XML dan RDF, as a data interchange format

3. Layer $S P A R Q L$, is a query language at the same protocols used in accessing the data on the semantic web.

4. Layer $R D F$ Schema dan $O W L$, is used to express the semantics of data and written in RDF format.

5. RIF (Rule Interchange Format), designed to address the problem of interoperability in the rule language used.

\subsection{Ontology}

Ontology is the key to implementing of semantic web [6]. Ontologies can be defined as "an explicit specification of a conceptualization" [7]. Ontology is very important to describe something. Technically, ontologies can be represented in the form of objects, properties of objects, and the relationship between each object [8]. Ontology is represented by the use of language OWL (Web Ontology Language), OWL Initially designed for representing information about the category of an object and how these objects relate. OWL can also provide information about the object itself. As a result of the work done by the W3C Semantic Web activity, OWL must be in accordance with the vision of the semantic web, the languages that are grouped together with XML and RDF [1].

\subsection{RDF}

RDF (Resource Description Framework) is an XML application that allows the preparation of a resource-rich description, structured, and can be read by machine. RDF is a framework to describe a web page. Each document is a collection of RDF statements composed of subject, predicate and object commonly known as triples. This set of statements if it is described to form a set of nodes that are connected by directional arrow-shaped edge so as to form a graph. There are several famous RDF serialization formats, including RDF / XML, Turtle (terse RDF Triple Language) and N-Triples.

\subsection{SPARQL}

SPARQL (SPARQL Protocol and RDF Query Language) is a query language used to access documents RDF. SPARQL is similar to that of the relational SQL database. SPARQL makes it possible to do several things, namely, taking the value of structured data and data that is semi-structured, developing the data by performing queries against a relation that is not known, perform a query join operation complex on databases different in a more simple, and transform the data RDF into another vocabulary. SPARQL example can be seen in figure 2.

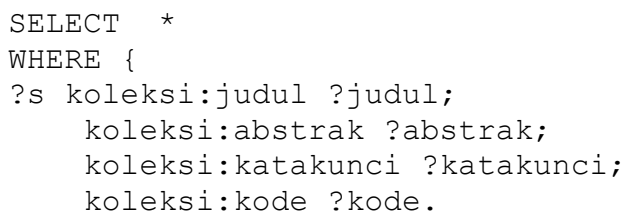

Figure 2. SPARQL Example

\section{RESEARCH METHODOLOGY}

In general, the stages in this study can be seen in Figure 3 .

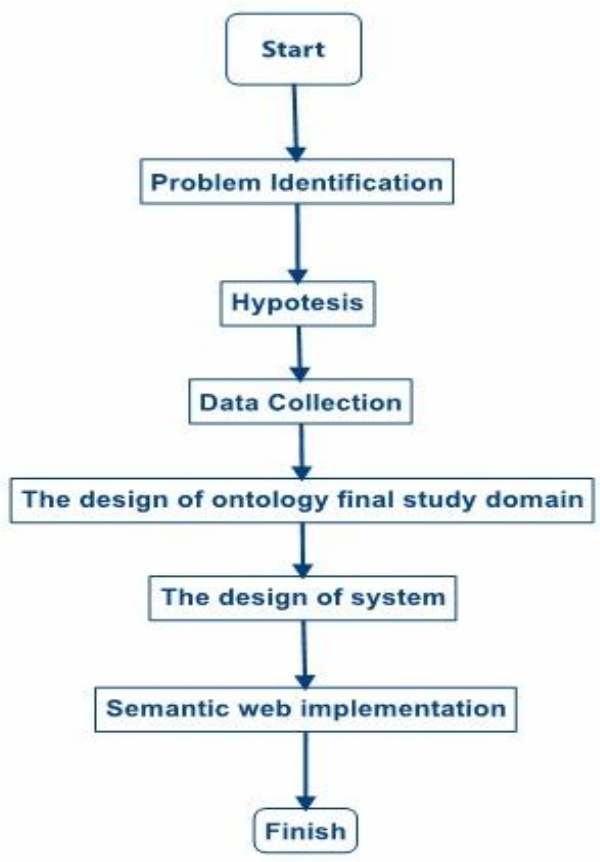

Figure 3. The research Steps

Figure 3 are steps in conducting the research, the following explanation of these steps

1. Identify the problem, at this step the identification of the issues involved, the problems that encourage research at the final study domain.

2. Hypothesis, this step determines the initial hypothesis that the semantic web can be applied at 
the end of the study domain to facilitate the search collection of the final study report based on knowledge.

3. Data collection, data collection associated with the final study domain.

4. The design of Ontology, at this step of the designed ontology based on the results of data collection has been done.

5. System Design, at this step of the design of the system interface.

6. Implementation, the next step is to implement the ontology and interface design becomes semantic web.

The tools and materials used include:

1. Data reports work practice and final project

2. Protégé

3. RDF Api

4. Notebook/PC.

\section{RESULTS AND DISCUSSION}

\subsection{Design of ontology}

At this step, domain ontology final study design students, this design uses protégé. Results of ontology design can be seen in Table 1 and Table 2.

Table 1. Class, SubClassOf dan ObjectProperty

\begin{tabular}{|c|c|c|}
\hline Class & SubclassOf & Object Property \\
\hline CivitasAkademik & Thing & \\
\hline Karyallmiah & Thing & dibimbingOleh \\
\hline Dosen & CivitasAkademik & \\
\hline Mahasiswa & CivitasAkademik & menulis \\
\hline KP & Karyallmiah & ditulisOleh \\
\hline TugasAkhir & Karyallmiah & ditulisOleh \\
\hline
\end{tabular}

Table 2. Data Property, Domain dan Range

\begin{tabular}{|c|c|c|}
\hline Data Property & Domain & Range/Value \\
\hline Nama & Dosen,Mahasiswa & Xsd:String \\
\hline Nip & Dosen & Xsd:String \\
\hline Nim & Mahasiswa & Xsd:String \\
\hline Abstrak & KP,TugasAkhir & Xsd:String \\
\hline Judul & KP,TugasAkhir & Xsd:String \\
\hline Katakunci & KP,TugasAkhir & Xsd:String \\
\hline Kode & KP,TugasAkhir & Xsd:String \\
\hline
\end{tabular}

\subsection{Design of semantic web user interface}

At the design step of this semantic web interface (Figure 4) there are 2 menu, the menu for the search KP / TA and full search menu.

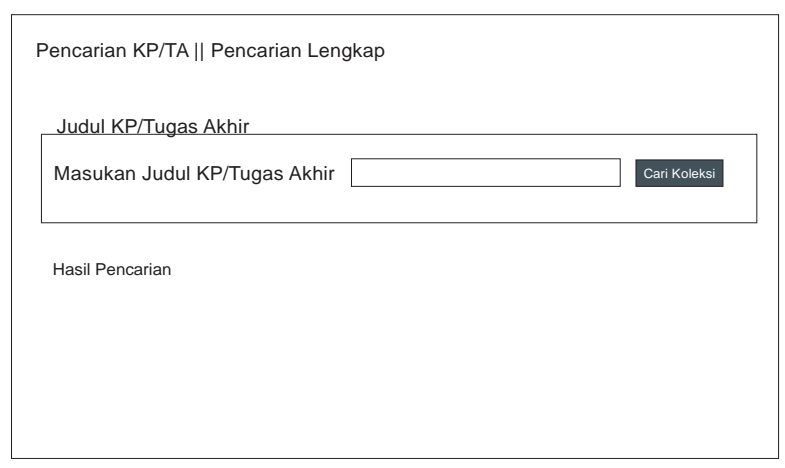

Figure 4. User interface

\subsection{Implementation of ontology}

After designing ontology in step 5.1, the next step is the implementation of the concept ontology using protégé

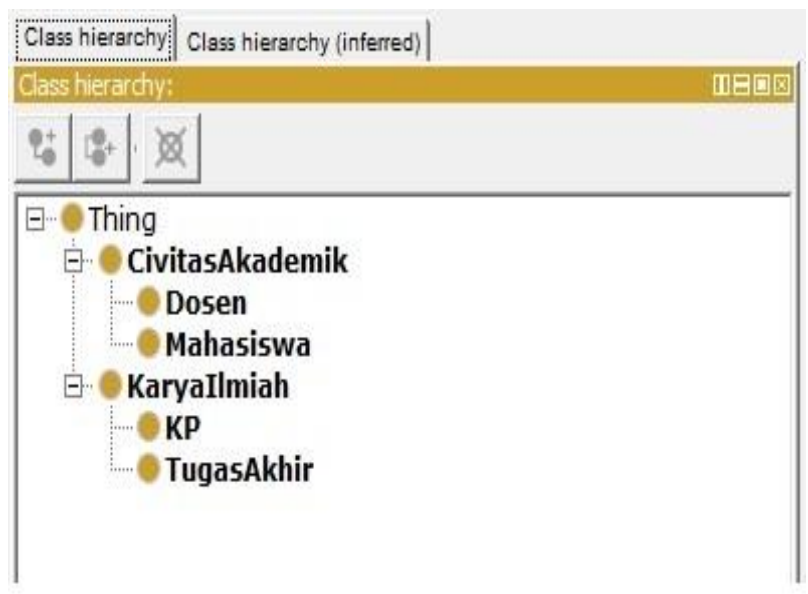

Figure 5. Implementation of ontology

At the end of the study design domain ontology produced two classes, as follows

1. Class CivitasAkademik, The $s$ CivitasAkademik Clas have two 2 subClass, there are Dosen and Mahasiswa.

2. Class KaryaIlmiah, the Karyallmiah Class have two subclass, there are KP and TugasAkhir.

Implementation of ObjectProperty can be seen in figure 6

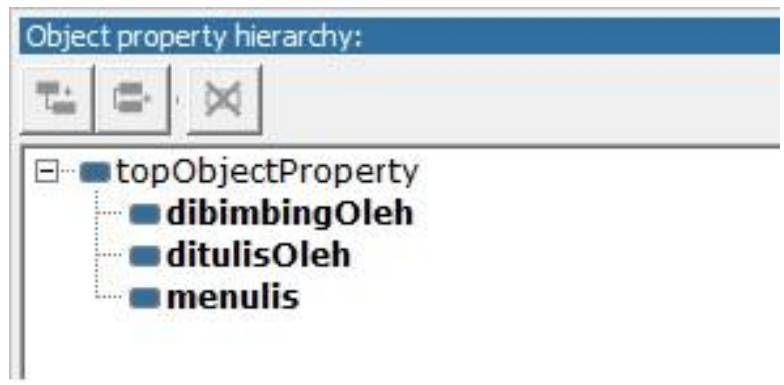

Figure 6. Implementation of Object Property 
1. dibimbingOleh, in which this property has domain Karyallmiah and Dosen Ranges

2. ditulisOleh, which have domain KP dan TugasAkhir with Mahasiswa ranges.

3. menulis,which domain Mahasiswa and Karyallmiah ranges.

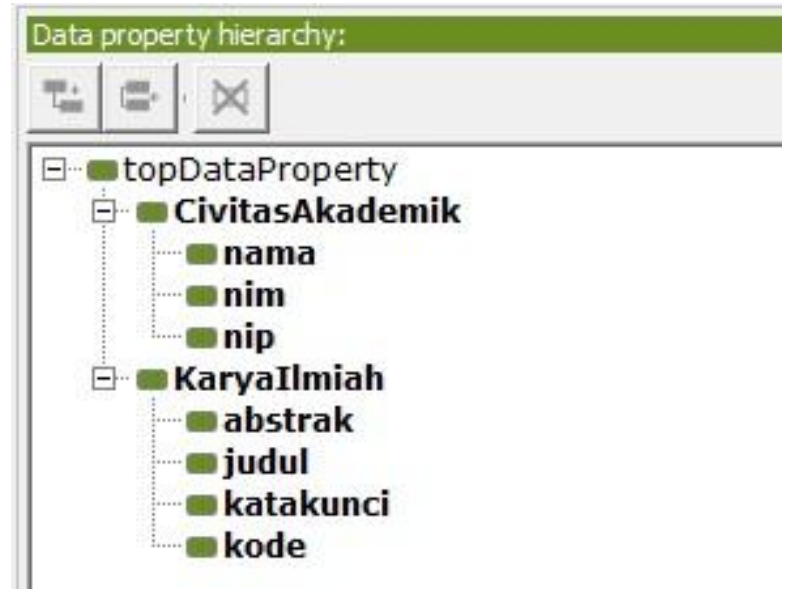

Figure 7. Implementasi Data Property

An overview of the implementation of the ontology can be seen in Figure 8

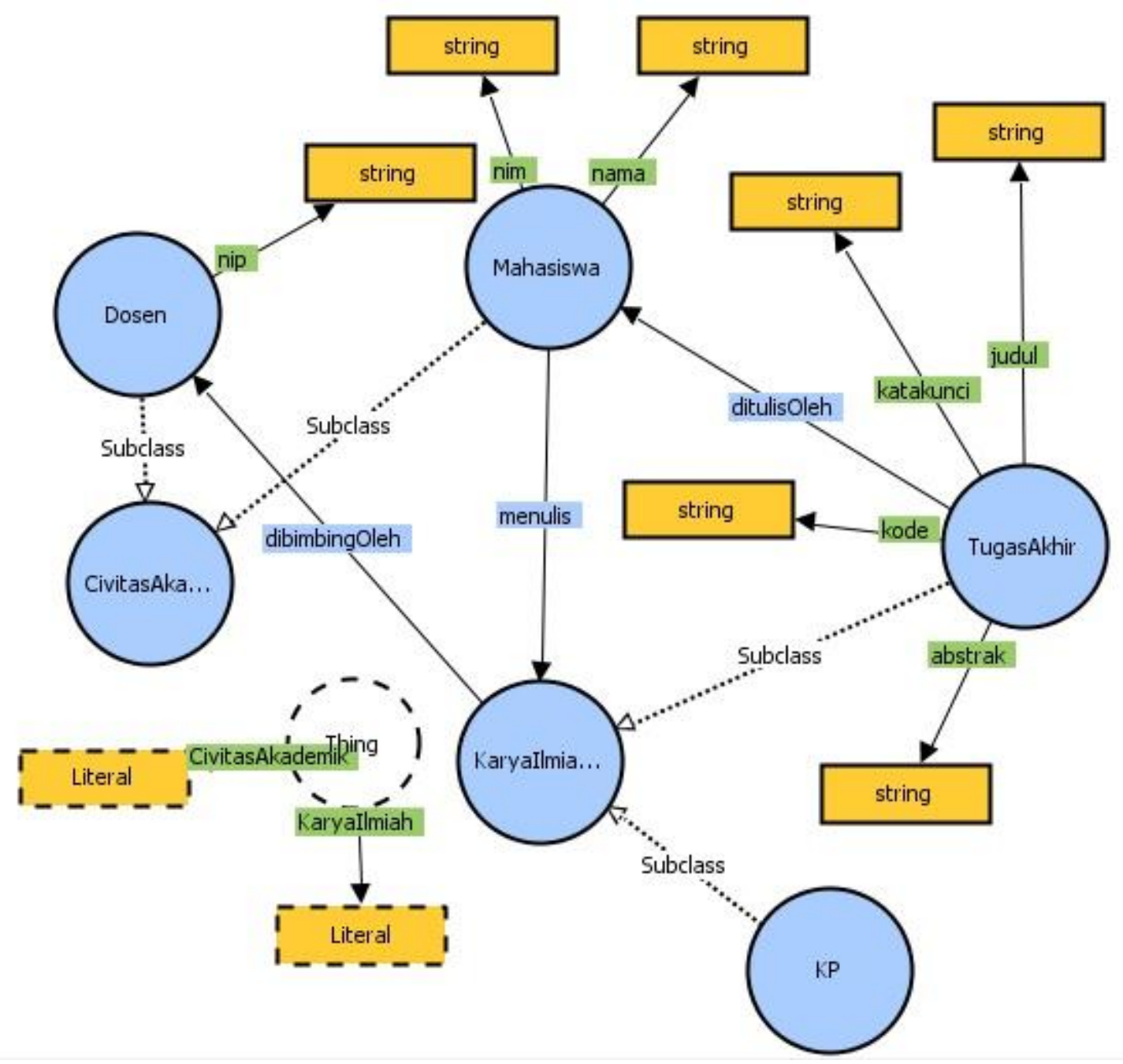

Figure 8. Ontology VOWL 


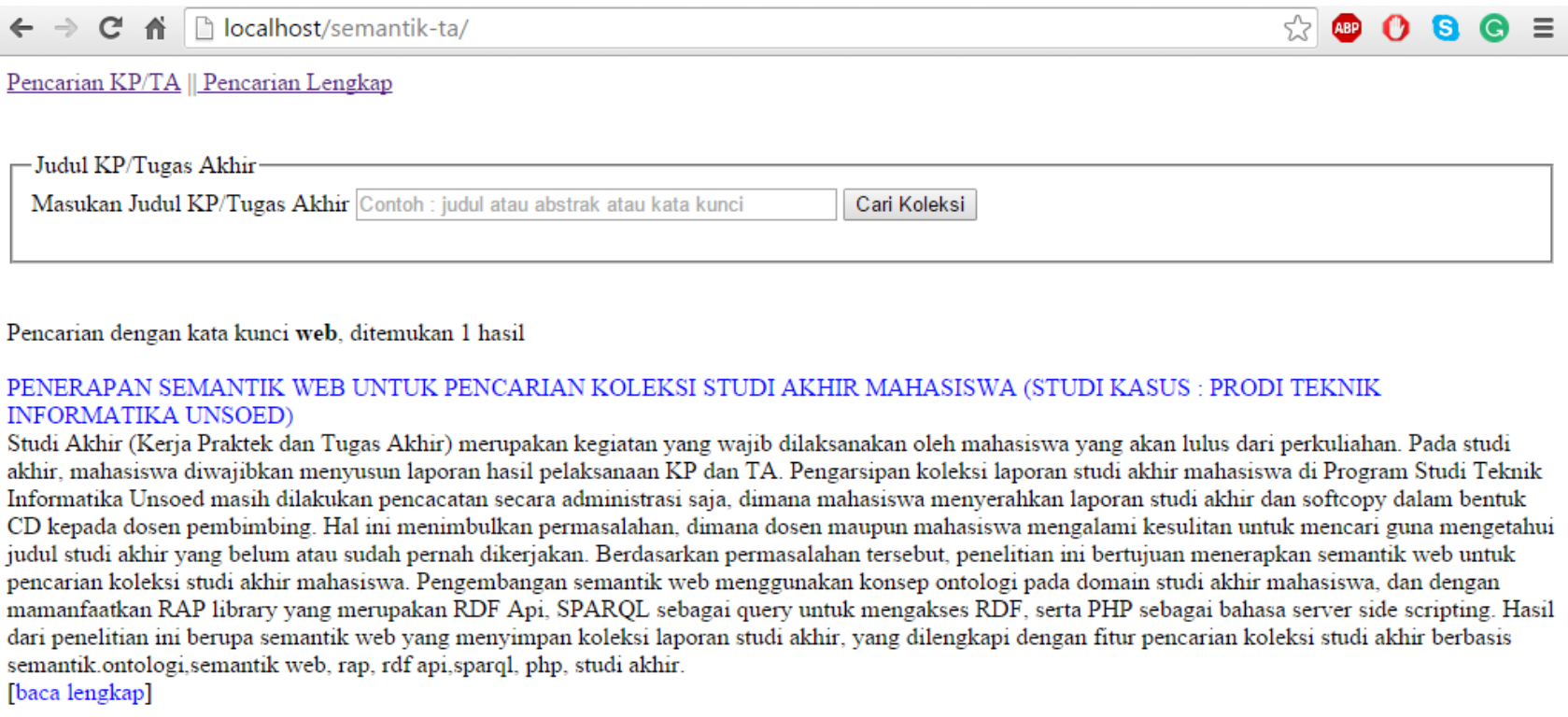

\section{Figure 9. Semantic web implementation}

\section{SPARQL example for search collections}

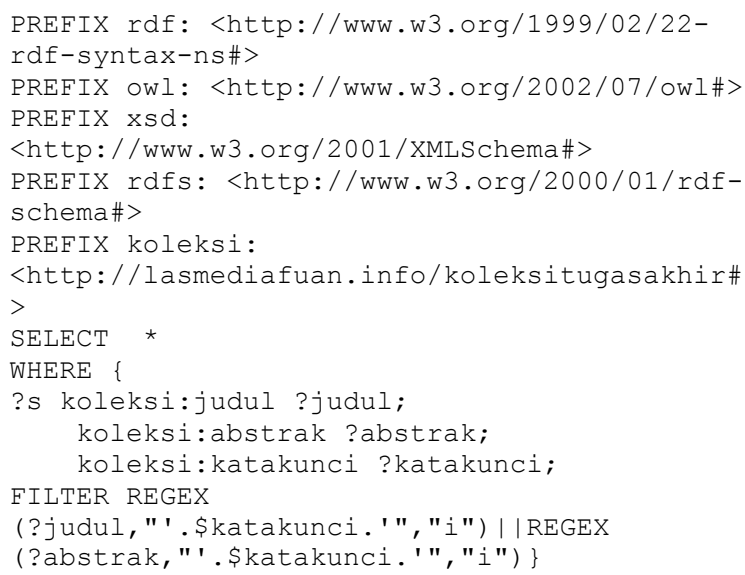

\section{CONCLUSION}

Based on the steps of the research, this study has managed to build a semantic web which can be used to search a collection of students' final study. For future work can be done modeling vocabulary search by adding keywords, so the search can be done with the synonym of a keyword. The addition of more data and a variety can be conducted to determine the inclination of the measurement results further. In addition, the application needs to implement SWRL.

\section{REFERENCES}

[1] H. F. Gunawan, "Penerapan Web Semantik Untuk Aplikasi Pencarian Pada Repositori Koleksi Penelitian ,Studi Kasus: Program Studi Sistem Informasi Stmik Mikroskil Medan," vol. 15, no. 1, pp. 51-60, 2014.

[2] I. A. S. Wicaksono, N. Charibaldi, and H. Jayadianti, "Penerapan Teknologi Semantic Web untuk Menentukan Pilihan Jalur Bis Trans Jogja," Semin. Nas. Inform. 2010 (semnasIF 2010), vol. 2010, no. semnasIF, pp. 102-110, 2010.

[3] K. I. Lakhtaria and M. Trivedi, "Providing Smart-Space to E-Commerce with Semantic Web," vol. 1, no. 1, pp. 27-34, 2011.

[4] Azhari Azhari and Minurita Sholichah, "Model Ontologi Untuk Informasi Jadwal Penerbangan Menggunakan Protégé,” J. Inform., vol. 7, no. 1, pp. 67-76, 2006.

[5] D. W. Jo, "Web-based Semantic Web Retrieval Service for Law Ontology," 2013.

[6] A. Gali, C. X. Chen, K. T. Claypool, and R. Uceda-sosa, "From Ontology to Relational Databases," pp. 1-12.

[7] T. R. Gruber, "A translation approach to portable ontology specifications," Knowl. Acquis., vol. 5, no. 2, pp. 199-220, 1993.

[8] B. Chandrasekaran, J. R. Josephson, and V. R. Benjamins, "What Are Ontologies , and Why Do We Need Them ?," 1999. 